\title{
ROLE OF FAT GRAFTING IN LATE BREAST RECONSTRUCTION AFTER FAILURE OF IMMEDIATE BREAST RECONSTRUCTION WITH IMPLANTS - EXPERIENCE OF HOSPITAL DE CLÍNICAS IN PORTO ALEGRE
}

\author{
Andréa Pires Souto Damin 1,2, Gabriela Dinnebier Tomazzoni', Angela Erguy Zucatto ${ }^{1,2}$, Maira Zancan', Jorge \\ Villanova Biazús² \\ 'Postgraduate Program In Ginecology And Obstetrics, Universidade Federal do Rio Grande do Sul - Porto Alegre (RS), \\ Brazil. \\ ${ }^{2}$ Serviço de Mastologia do Hospital das Clínicas de Porto Alegre - Porto Alegre (RS), Brazil.
}

Introduction: The breast reconstruction techniques with tissue expanders and silicone implants were the most used ones in the past decade. Immediate post-mastectomy reconstruction can evolve to loss of implants, causing significant morbidity to the patients. The knowledge of techniques that use fat grafting has allowed the use of more late reconstruction techniques. Objectives: To assess the application of fat grafting in late breast reconstruction in patients submitted to mastectomy with immediate reconstruction, who presented loss of implant (expanders and prostheses). Method: Crosssectional study carried out through data collection in electronic medical records. We selected patients from the Mastology Service in HCPA, submitted to immediate breast reconstruction with expanders/prostheses in the period from May/2000 to May/2019. Results: We analyzed 241 cases of mastectomy with immediate breast reconstruction based on implants 127 (52.7\%) expanders and 114 (42.3\%) direct prosthesis. In 24 cases (10.0\%), there was loss of implants. Among these 24 patients, $20(83.3 \%)$ had not undergone radiotherapy before mastectomy, and $4(16.7 \%)$ had been submitted to previous radiotherapy. Of these, in 18 cases $(75.0 \%)$, late reconstruction was performed: 3 cases $(20.8 \%)$ of reconstruction with rectus abdominis flap (TRAM), 4 cases (23.4\%) of reconstruction with latissimus dorsi muscle flap (LD), 1 case (5.5\%) of fat grafting with flap planning, 6 cases (33.6\%) of exclusive flap grafting, and 4 cases (23.4\%) of expander/prosthesis after the plastron fat grafting. Conclusions: Breast reconstruction after the loss of expanders/prosthesis can be carried out through several surgical techniques. The knowledge of the mastologist about the different techniques aims at providing the best choice to be used, according to the individual risk profile of each patient. Plastron fat grafting after loss of implant is an important ally in late reconstruction, improving the local conditions and allowing, in our sample, the prevention of the indication of flaps $57 \%$ of the time. 